\title{
Stress Concentration of Rectangular Plate with a Hole Made With Composite Material Using Finite Element Analysis
}

\author{
Dr.Abdul siddique shaik ${ }^{1}$, Ishrat Meera Mirzana ${ }^{2}$ \\ ${ }^{I}$ Mechanical Engg. Dept., King Khalid University, Abha, Kingdom of Saudi Arabia. \\ ${ }^{2}$ Mechanical Engg. Dept., Muffakham Jah College of Engg. \& Tech., Hyderabad, India.
}

\begin{abstract}
A rectangular plate with a central hole have initiate extensive practical applications in different fields of engineering such as aerospace, marine, automobile and mechanical and is well-known to most engineers. High stress due to discontinuity or abrupt change in geometry is known as stress concentration and is mostly set up at the edges of discontinuity. A stress concentration is typically introduced in plates in the form of circular holes. For the design of plate with a hole, proper knowledge of stresses and stress concentration factor (SCF) at the edge of hole under in plane loading are essential. In this project an attempt is made to review the investigations that have been made on the "stress analysis of a rectangular plate with circular hole". Finite Element simulations using Ansys have been done for stress analysis around the circular hole, made up of different materials. The materials considered are composite material i.e carbon / epoxy and also with mild steel. Keywords: Stress concentration factor, Finite element analysis, Carbon / epoxy
\end{abstract}

\section{Introduction}

A composite material can be defined as a combination of two or more materials that results in better properties than those of the individual components used alone. In contrast to metallic alloys, each material retains its separate chemical, physical, and mechanical properties. The two constituents are reinforcement and a matrix. The main advantages of composite materials are their high strength and stiffness, combined with low density, when compared with bulk materials, allowing for a weight reduction in the finished part. A fiber has a length that is much greater than its diameter. The length-to-diameter $(l / d)$ ratio is known as the aspect ratio and can vary greatly. Continuous fibers have long aspect ratios, while discontinuous fibers have short aspect ratios. Continuous-fiber composites normally have a preferred orientation, while discontinuous fibers generally have a random orientation [5].

The origin of this study lies within the framework of an industrial agreement to study the behaviour of composite materials (carbon/epoxy) used in structural work in the field of aeronautics. In order to anticipate possible problems of mechanical resistance and life span on these materials, a series of static fatigue tests and finite element study have been planned. The objective here is to calculate stress concentration around a circular hole in the composite plate under longitudinal tensile load. The increasing use of composite materials in the design of structural parts with high mechanical performance requires a better understanding and modeling the behavior of these structures. Holes in composites will create stress or strain concentrations and hence will reduce the mechanical properties [1]. A ESPI technique has been used to study the strain concentration round a measurement of the three-dimensional displacement field on the specimen surface. The deformation of the surface of the specimen due to the applied load is seen by a change of the attached random grating [2,3]. The advantages of the ESPI technique are the accuracy and spatial resolution of the measurement (in the micron meter range), a larger measurement area than the measurement area of strain gages, and a noncontact measurement.

\section{Material Selection}

Material selection is a step in the process of designing any physical object. In the context of product design, the main goal of material selection is to minimize cost while meeting product performance goals.[4] Systematic selection of the best material for a given application begins with properties and costs of candidate materials. For example, a thermal blanket must have poor thermal conductivity in order to minimize heat transfer for a given temperature difference. The materials chosen consisted of carbon fiber reinforced composites with epoxy resin matrix are shown in table 1.

Table 1: Material Properties of Carbon/Epoxy for different fiber angles

\begin{tabular}{|l|l|l|l|l|l|}
\hline Fiber Angle & Exx $(\mathrm{GPa})$ & Eyy $(\mathrm{GPa})$ & vxy & vyz & Gxy $(\mathrm{GPa})$ \\
\hline $0^{0}$ & 82.64 & 9.8034 & 0.3 & 0.0356 & 3.8545 \\
\hline $30^{0}$ & 67.2251 & 14.4947 & 0.3 & 0.0356 & 7.798 \\
\hline $45^{0}$ & 53.962 & 19.943 & 0.3 & 0.0356 & 10.6146 \\
\hline $60^{0}$ & 42.9766 & 26.3346 & 0.3 & 0.0356 & 12.3027 \\
\hline $90^{0}$ & 33.9035 & 33.9035 & 0.3 & 0.0356 & 12.8642 \\
\hline
\end{tabular}


A. Steps involve in Ansys:

\section{Finite Element Analysis}

Preprocessor: All inputs like element selection, real constrain, material properties (young's modulus, poisons ratio, shear modulus) and meshing of the design is given here. And FE analysis is carried out in the solution.

Solution: The boundary conditions like displacement and axial load are given here. And the results are obtained in general post processor.

\section{General Post Processor:}

In post processors the results obtain are

$>$ Deformation

$>$ Von mises Stress \& Strain

$>$ Principle Stress \& Strain

\section{B. FE Analysis of Rectangular Plate with Central Hole for Mild Steel}

ANSYS 11 has been implemented to solve the present problem considering an axial force of $5 \mathrm{KN}$ the element type selected for performing the analysis is quar 4 node 42 material selected was mild steel. The analysis is carried on rectangular plate with central hole of dimensions $200 \mathrm{~mm} * 100 \mathrm{~mm} * 2 \mathrm{~mm}$ and the diameter of hole is $30 \mathrm{~mm}$. The simulated results are shown in figures $1 \& 2$. Consolidate results are tabulated in table 2.

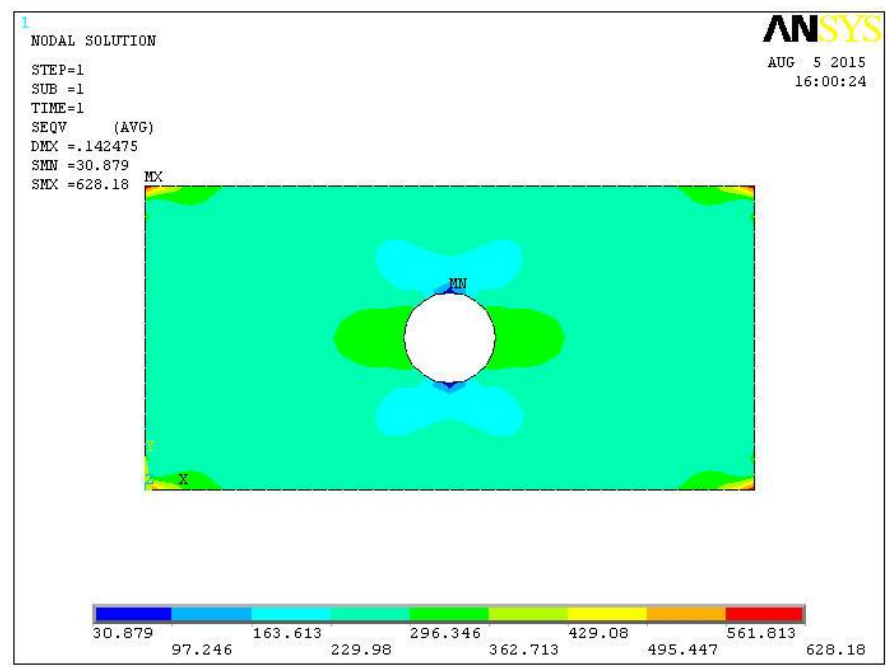

Fig 1: Von mises stress of mild steel plate

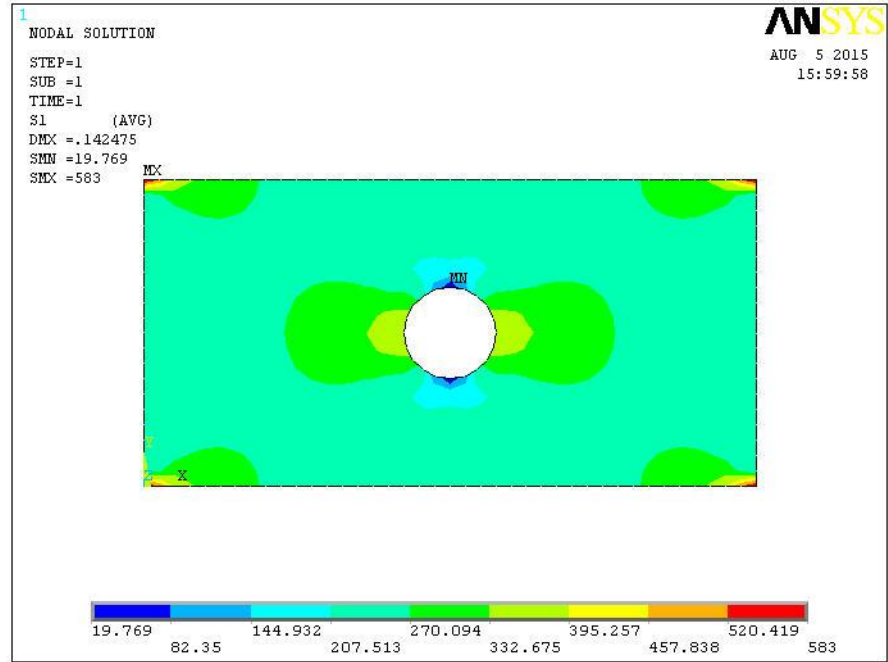

Fig 2: Principle stress of mild steel plate 
Stress Concentration Of Rectangular Plate With A Hole Made With Composite Material Using...

Table 2: Ansys \& Theoretical results of mild steel plate with $\%$ of variation

\begin{tabular}{|l|l|l|l|}
\hline & Ansys & Theoretical & \% of Variation \\
\hline Deformation (mm) & 0.142 & - & - \\
\hline Von Stress (N/mm $\left.{ }^{2}\right)$ & 628 & 772 & $18 \%$ \\
\hline Principal Stress $\left(\mathbf{N} / \mathbf{m m}^{2}\right.$ ) & 583 & - & - \\
\hline Stress Intensity Factor & 1.908 & 2.347 & \\
\hline
\end{tabular}

\section{FE Analysis of Rectangular Plate with Central Hole for Carbon/Epoxy}

ANSYS 11 has been implemented to solve the present problem considering an axial force of 5KN and the element selected for performing the analysis is Shell element. The analysis is carried on rectangular plate with central hole of dimensions $200 \mathrm{~mm} * 100 \mathrm{~mm} * 4 \mathrm{~mm}$ and the diameter of hole is $30 \mathrm{~mm}$. The simulated results are shown in figures $3 \& 4$. Consolidate results are tabulated in table 3.

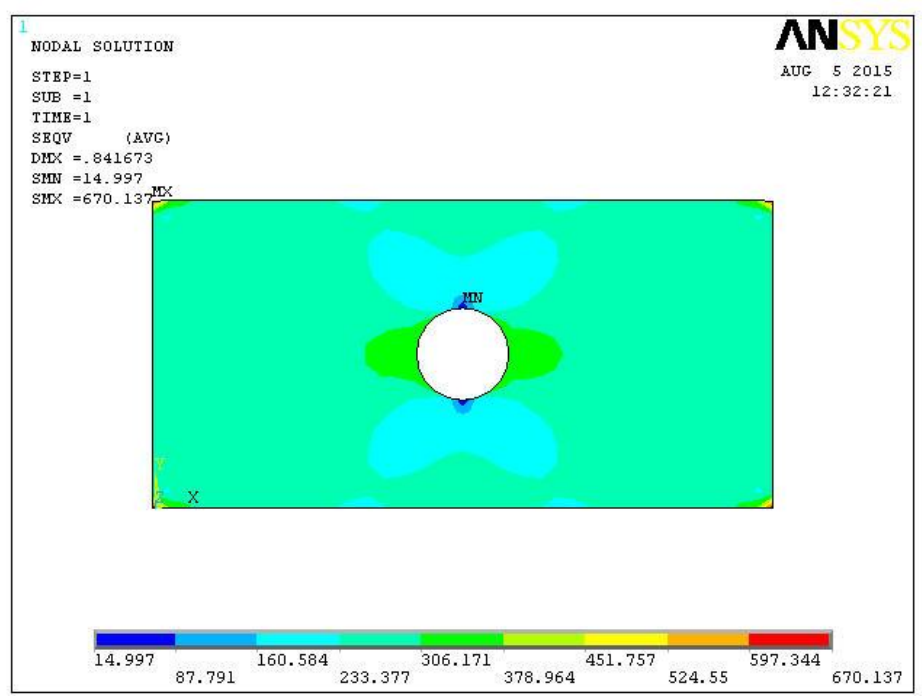

Fig 3: Von mises stress of carbon/epoxy at $90^{\circ}$

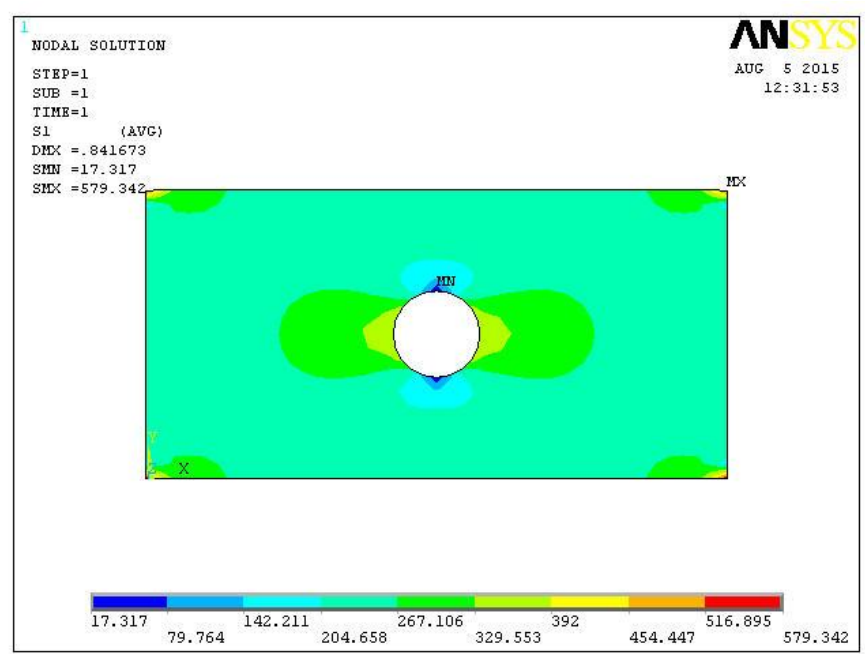

Fig 4: Principle stress of carbon/epoxy at $90^{\circ}$

Table 3: Consolidate results of different fiber angles of carbon/epoxy

\begin{tabular}{|l|l|l|l|l|}
\hline $\begin{array}{l}\text { Fiber } \\
\text { Angle }\end{array}$ & $\begin{array}{l}\text { Deformation } \\
(\mathbf{m m})\end{array}$ & $\begin{array}{l}\text { Principle Stress } \\
\left(\mathbf{N} / \mathbf{m m}^{2}\right)\end{array}$ & $\begin{array}{l}\text { Von Mises Stress } \\
\left(\mathbf{N} / \mathbf{m m}^{2}\right)\end{array}$ & $\begin{array}{l}\text { Stress Intensity } \\
\text { Factor }\end{array}$ \\
\hline $0^{0}$ & 2.71 & 855 & 929 & 1.9115 \\
\hline $30^{0}$ & 1.95 & 756 & 737 & 1.8658 \\
\hline $45^{0}$ & 1.23 & 623 & 702 & 1.9445 \\
\hline $60^{0}$ & 0.88 & 591 & 682 & 1.9625 \\
\hline $90^{0}$ & 0.84 & 579 & 670 & 1.956 \\
\hline
\end{tabular}




\section{Results And Discussions}

Rectangular plate with central hole of dimensions $200 \mathrm{~mm} * 100 \mathrm{~mm} * 4 \mathrm{~mm}$ and the hole diameter is analyzed by using carbon epoxy with different fiber angles like $0^{\circ}, 30^{\circ}, 45^{\circ}, 60^{\circ}, 90^{\circ}$ and found the better fiber angle to determine the stress concentration. The consolidate results are tabulated in table $4 \& 5$ and the graphs are shown in fig 5 to fig 7.

Table 4: Consolidate results of different fiber angles of carbon/epoxy

\begin{tabular}{|l|l|l|l|l|}
\hline $\begin{array}{l}\text { Fiber } \\
\text { Angle }\end{array}$ & $\begin{array}{l}\text { Deformation } \\
(\mathbf{m m})\end{array}$ & $\begin{array}{l}\text { Principle Stress } \\
\left(\mathbf{N} / \mathbf{m m}^{2}\right)\end{array}$ & $\begin{array}{l}\text { Von Mises Stress } \\
\left(\mathbf{N} / \mathbf{m m}^{2}\right)\end{array}$ & $\begin{array}{l}\text { Stress Intensity } \\
\text { Factor }\end{array}$ \\
\hline $0^{0}$ & 2.71 & 855 & 929 & 1.9115 \\
\hline $30^{0}$ & 1.95 & 756 & 737 & 1.8658 \\
\hline $45^{0}$ & 1.23 & 623 & 702 & 1.9445 \\
\hline $60^{0}$ & 0.88 & 591 & 682 & 1.9625 \\
\hline $90^{0}$ & 0.84 & 579 & 670 & 1.956 \\
\hline
\end{tabular}

\section{Deformation}

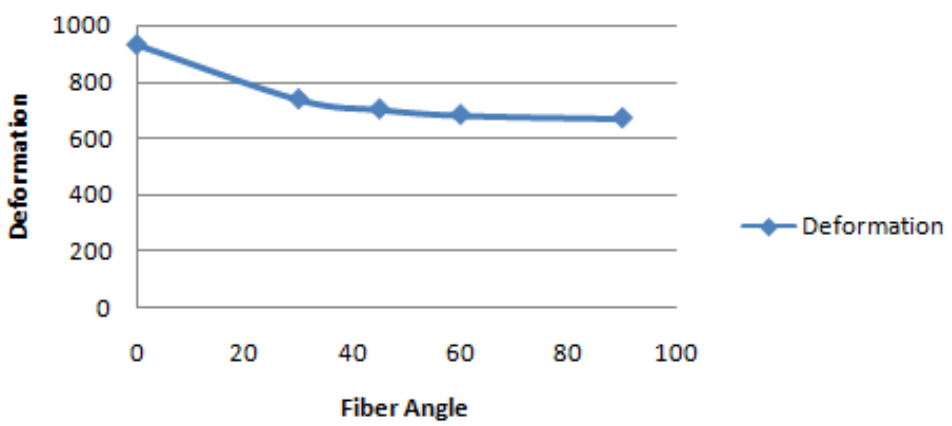

Fig 5: Graphs shows the deformation of plate made Carbon/epoxy at different fiber angles

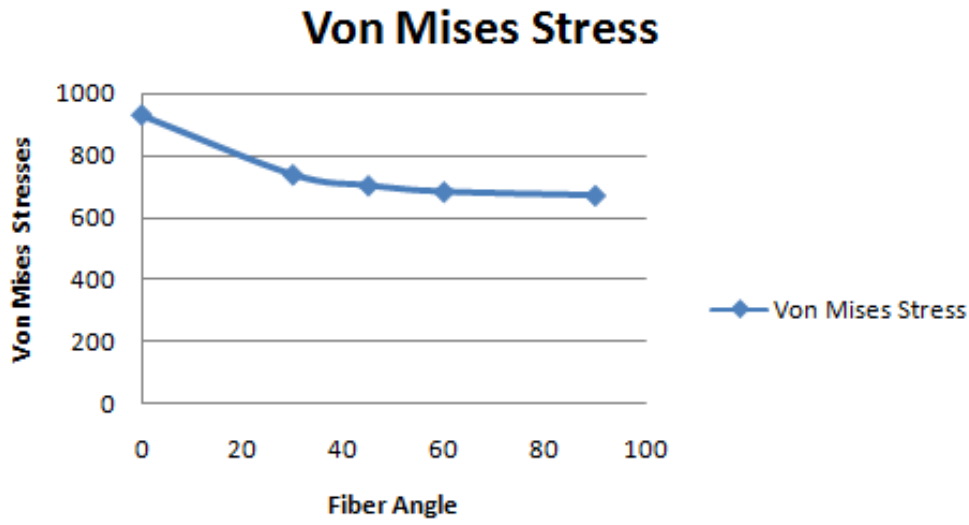

Fig 6: Graph shows the von mises Stress of plate made Carbon/epoxy at different fiber angles

\section{SCF}

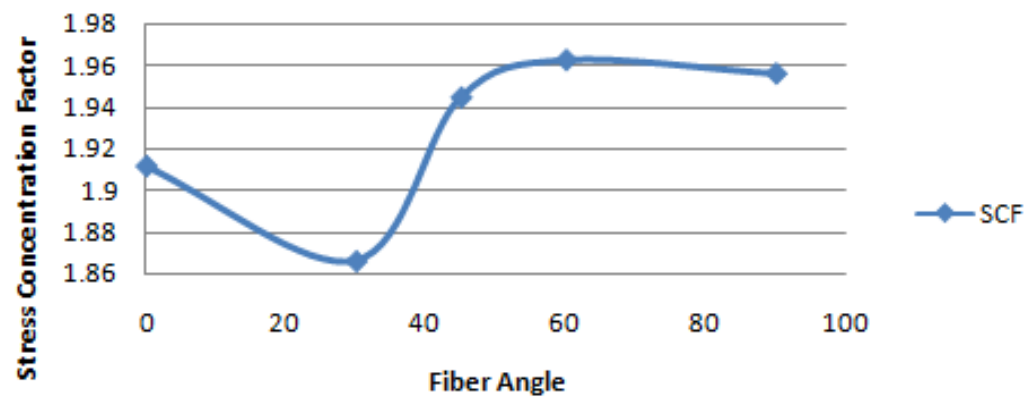

Fig 7: Graphs shows the SCF of carbon/epoxy at different fiber angles 
From the above results the better results are obtained at fiber angle $90^{\circ}$ in both the materials Carbon/epoxy. Now these results of fiber angle $90^{\circ}$ are compared with mild steel plate as tabulated in table 5. If we talk about the stress intensity factor fiber angle $30^{\circ}$ has less concentration compare to other fiber angles as shown in fig 8 . And the same $30^{\circ}$ fiber SIF is less than the MS plate SIF.

Table 5: Comparison results of carbon/epoxy and mild steel

\begin{tabular}{|c|c|c|c|}
\hline Materials & Carbon/epoxy $\left(90^{\circ}\right)$ & Carbon/epoxy $\left(30^{0}\right)$ & Mild steel \\
\hline Deformation (mm) & 0.84 & 1.95 & 0.142 \\
\hline Von Mises Stress (N/mm²) & 670 & 755 & 628 \\
\hline Principle Stress $\left(\mathbf{N} / \mathbf{m m}^{2}\right)$ & 579 & 737 & 583 \\
\hline Stress Concentration Factor & 1.956 & 1.8658 & 1.908 \\
\hline
\end{tabular}

\section{Stress Concentration Factor}

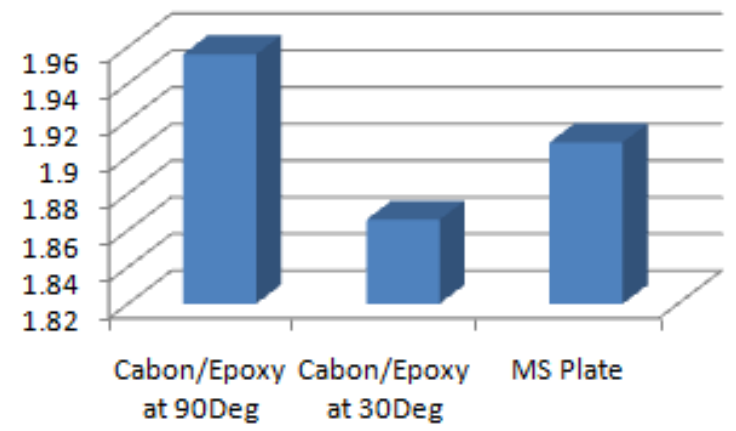

Stress Concentration

Factor

Fig 8: Graphs shows the SCF of carbon/epoxy and MS plates

\section{Conclusion}

In general, the maximum stress concentration is always occurred on hole boundary in a finite width plate with central hole under in-plane static loading. The SCF is maximum at the tip of the hole (perpendicular to loading).

- From the results it is concluded that $30^{0}$ fiber is the optimum fiber where SCF is less than the other fiber angles.

- Where comes to other angles $0^{\circ}$ holds good in stress and $90^{\circ}$ in deflection.

- The suitable optimum fiber angle for rectangular plate with central hole when working with composite materials is $30^{\circ}$.

\section{Reference}

[1]. Pandit SD, Nishiyabu K, Verpoest I. Strain concentrations in woven fabric composites with holes. Compos Struct 2003;59:361-8.

[2]. Icardi U. Through-the-thickness displacements measurement in laminated composites using electronic speckle photography. Mech Mater 2002;35:35-51.

[3]. Marchetti E, Faraggiana R, Bonifacio P. A speckle interferometry survey of Bootis stars. A\&A 2001;370:524-8.

[4]. George E. Dieter (1997). "Overview of the Materials Selection Process", ASM Handbook Volume 20: Materials Selection and Design

[5]. Structural Composite Material by F.C. Campbell, ASM International (Text Book)

[6]. Dheeraj Gunwant, J.P. Singh, "Stress and Displacement Analysis of a Rectangular plate with Central Elliptical Hole", International Journal of Engineering and Innovation Technology (IJEIT), ISSN:2277-3754, Volume 3, Issue 3, September 2013, PP: 387-392

[7]. Dr. Riyah N.K, Mr. Ahmed N.E., "Stress Analysis of Composite Plate with Different Types of Cutouts", Anbar Journal of Engineering (AJES-2009), Vol 2, No. 1, PP: 11-29.

[8]. MOON BANERJEE, N. K. JAIN \& S. SANYAL, "Stress Concentration In Isotropic \& Orthotropic Composite Plates With Center Circular Hole Subjected To Transverse Static Loading”, International Journal of Mechanical and Industrial Engineering (IJMIE) ISSN No. 2231-6477, Vol-3, Iss-1, 2013, PP: 109-113

[9]. N D Mittal \& N K Jain, "Effect of Fiber Orientation on Stress Concentration Factor in a Laminate with Central Circular Hole Under Transverse Static Loading", Indian Journal of Engineering and Materials Sciences, Vol. 15, December 2008, PP: 452-458

[10]. K. Ting, K. T. Chen, and W. S. Yang, "Stress analysis of the multiple circular holes with the rhombic array using alternating method," International Journal of Pressure Vessels and Piping, vol. 76, pp. 503- 514, 1999.

[11]. R. A. Chaudhuri, "Stress concentration around a part through hole weakening laminated plate," Computers \& Structures, vol. 27(5), pp. 601-609, 1987 